\title{
Modernidade(s) e religião: Rupturas, permanências e combinações
}

\author{
Emerson José Sena da Silveira* \\ EduARdo José CROCHeT**
}

\begin{abstract}
Resumo : Refletir sobre a modemidade e sua relação com a religião é pensar o papel da tradição, as transformações em aurso na esfera da cultura e as suas repercussões na manifestação das diversas religiosidades. Nesse sentidb, é preciso desnaturalizar conceitos camo o de modemidade, demonstrando a existência de significados plurais nas dbbras do conceito e da realidade. Aponta-se, assim, para novas possibilidades, como a hibridação entre crenças e práticas alturais e religiosas.
\end{abstract}

Palavras-chave : modemidade(s); religião; teorias sociais; campo religioso brasileiro.

\section{Introdução}

Tendo como objetivo subsidiar as discussões em torno do tema "modernidade(s) e religião", o presente texto trata-se de uma exposição de referenciais teóricos da sociologia e da antropologia, que não pretende esgotar o tema, mas nortear o debate para que, este sim, tornese profícuo no surgimento de novas questões e investigações.

"Modernidade(s)", tal como é apresentada, indica desde já o caráter plural desse conceitochave, nele mesmo ou na relação com seu oposto "tradição". A essa idéia, articulam-se várias outras que se fizeram surgir na seqüência dos debates cada vez mais abrangentes e criteriosos. Modernidades cumulativas, pósmodernidade, modernidade tardia, pós-

\footnotetext{
* Antropólogo, mestre e doutorando em Ciência da Religião pela Universidade Federal de Juiz de Fora. Membro do CEHILA/Brasil. Integrante do Núcleo CEHILA-Juiz de Fora. Professor de sociologia e antropologia. E-mail: emerson. jsena@terra.com.br.

** Historiador. Formado em Filosofia pelo ITASA/JF. Mestre em História Social (UFRJ). Membro do CEHILA Brasil. Coordenador do Núcleo CEHILA-Juiz de Fora. Professor de Filosofia, Colégio Militar - Juiz de Fora. e-mail: eduardocrochet@terra.com.br.
}

tradicionalidade, tradições modernas, tradições inventadas, destradicionalização são apenas algumas que, por ora, podem ser citadas. A elas se ajunta mais um sem-número de conceitos caso esteja a se referir às relações que esta(s) modernidade(s) estabelece(m) com a "memória", a "cultura" ou a "religião" (hibridação, mescla e quebra dos sistemas culturais, reflexibilidade, convencionalização, desterritorialização, sincretismo).

Diante disso, pode-se perceber o quão difícil é penetrar no território, muitas vezes confuso à primeira vista, dessa discussão, sem alguns marcos referenciais que possam servir de guia. Por essa razão, o roteiro do presente texto segue uma categorização da modernidade ou modernidades, que levará ao debate do que, então, pode-se chamar (ou não) de "pós-modernidade". Daí, partir-se-á para uma apreciação das diversas relações possíveis entre tradição e modernidade, para então se vislumbrarem novos instrumentos conceituais acerca do fenômeno que, de fato, quer-se observar. Por fim, com a bagagem repleta, volver-se-á o olhar para um novo panorama histórico do campo religioso brasileiro. 


\section{Alguns instrumentos teóricos para com- preensão da(s) modernidade(s)}

Quando a "modernidade(s)", grafada dessa forma, é assumida, parte-se do seguinte pressuposto: não se pode dizer que exista apenas uma modernidade, e sim várias. Mas também não se pode perder de vista a especificidade de cada uma delas, de acordo com o contexto histórico. Assim, com Pierre Sanchis, percebe-se que modernidade deve ser compreendida como uma relação, contudo não-necessária, entre um "presente" e um tempo ido considerado como "passado". Assim, pode-se notar que "não existe, em si, uma modernidade; sempre se é moderno de alguém" (Sanchis, 1992, p. 43). Só há modernidade, entendida como relação, quando o presente se inaugura com o seu valor próprio, isto é, como um novo, em critério de julgamento do passado. A idéia de Modernidade, conseqüentemente, pressupõe essa valorização do presente, "momento e locus da apreensão" do movimento histórico ascendente, em escala de valor, que vai do passado para o futuro.

A cultura ocidental, na qual se está inserido, caracteriza-se mais propriamente por essa valorização do "novo", com relação ao "passado" ou ao "tradicional". Em outras, é a referência à tradição que confere valor ao presente e permite a apreensão do futuro como repetição. Há, no contexto da globalização, uma necessidade antropológica de se trabalhar com o conceito de "tradição restaurada", para se compreender como essas culturas lidam com um fenômeno interno ou externo que ocasione mudanças radicais, posto que a novidade estabelecida, para se legitimar, deve ser considerada como um retorno ao passado.

Sanchis considera que "a nossa civilização é a civilização da modernidade". Para esse autor, a sistemática da modernidade marca definitivamente o nosso imaginário, o nosso sistema de percepção e nossa escala de valor (Sanchis, 1992, p. 43). De fato, Sanchis inspira-se na reflexão desenvolvida por Lima Vaz acerca do esquema filosófico que chamou de "modernidades sucessivas ou cumulativas", segundo o qual existiria, no Ocidente, uma permanente conjuntura de atualizações do passado, que definiria a forma de encarar a História como "um amadurecimento do tempo" (Sanchis, 1992, p. 44).

Ainda com Lima Vaz, descobre-se que o início desse ciclo de modernidades inaugura-se com a passagem do mito para a razão, como fonte de explicação do universo e do homem, uma vez que o homem toma consciência de uma relação entre ele próprio e o universo das coisas de tipo inteiramente novo. "A aventura epistemológica e histórica do homem ocidental começa com a modernidade grega" (Vaz, 2002, p. 8691).

No domínio da História, as modernidades que se seguem acompanham o movimento da tomada de consciência de si próprio pelo homem, seja com o advento da civilização urbana (Renascimento Carolíngio, do século IX) e a institucionalização da reflexão sistemática nas universidades (século XII), seja com a efervescência racional, política e estética do século XIII, ou ainda, com a Devotio Moderna, os Estados modernos, a Ars Nova e o Novum Organum de Bacon, durante os séculos XIV e XV. Essas modernidades sucessivas, experimentadas e auto-analisadas como tais, culminam com a irrupção tríplice, em religião, com a Reforma, em antropologia, com o Renascimento, em cosmografia e geografia, com o mundo copernicano, de um lado, e, enfim, com o Novo Mundo (Sanchis, 1992, p. 44).

Se existe sempre essa sucessão permanente de valorização do "novo", entendido como "moderno" em relação a um "antigo ultrapassado", e se a isso chamar-se de modernidade, ora, equivale dizer que não há modernidade alguma e, ainda, que falar em pós-modernidade não faz sentido algum.

Nesse ponto, Lima Vaz (2002) acrescenta a sua reflexão uma "inflexão fundamental e significativa" que legitima falar de uma modernidade, sem margens para ambigüidades. Tratase do desdobrar, em várias etapas, de um mesmo princípio transformador, isto é, o indivíduo. Esse desdobramento caracteriza a "modernidade moderna", marco divisório do processo de sucessão das modernidades,

cuja radicalidade e profundidade é possível discutir, sem dúvida [...], mas cuja existência é difícil negar entre, de um lado, o nosso próprio 
passado e nós mesmos e, por outro lado, entre a nossa civilização e o que eram as outras antes que a nossa as atingisse e as marcasse de sua imagem. (Sanchis, 1992, p. 45)

Os fundamentos dessa "modernidade moderna", ou a própria Modernidade para Lima Vaz, expressam-se historicamente pela rejeição de Lutero da autoridade eclesial em favor de uma reconsideração criteriosamente individual das Escrituras, pela radicalização cartesiana de si mesmo como ponto de partida absoluto para a reconstrução noética do mundo e pela declaração realizada pelos revolucionários franceses de que eram um "povo" e uma "Nação" pela exclusiva determinação livre de cada um dos cidadãos. A Razão por princípio, o Indivíduo por ator, a Liberdade por instrumento e condição, são essas as bases para o advento do "homem moderno". Este se reconhece como Sujeito infundado, diante de um mundo cujo conhecimento constitui uma verdadeira operação de “criação de mundo" (Vaz, 2002, p. 94).

A "modernidade moderna", "ao mesmo tempo em que fragmenta as instâncias e os objetos do conhecimento para abordá-los com uma inexorável eficácia transformadora, tende paradoxalmente a globalizá-los em grandes sínteses explicativas e projetivas" (Sanchis, 1992, p. 45). Pensa-se, por exemplo, no positivismo e no marxismo que, de formas distintas, procuram descobrir leis históricas que justifiquem as grandes transformações e indiquem o advento de um mundo inteiramente racional, oriundo do projeto consciente e voluntário de uma humanidade formada por indivíduos livres.

Lima Vaz (2002), continuando a sua reflexão sobre o tema, na coletânea de textos reunidos sob o título Escritos de filosofia VII - Raizes da Modernidade, desenvolve a hipótese de que a chamada Modernidade, compreendida como essa nova etapa na história intelectual do Ocidente, encontra algumas de suas raízes, sobretudo as de natureza metafísica, nas controvérsias doutrinais dos últimos anos do século XIII. O filósofo, em dezesseis capítulos que tratam das crises que abalaram o século XIII, realiza uma reflexão que se move "[...] no terreno da dialética fundamental cujos termos estruturam o sentido e orientam o desenrolar daqueles acontecimentos fundadores: continuidade e descontinuidade, primeiramente entre mito e razão, depois entre filosofia antiga e teologia cristã e, finalmente, entre teologia cristã e razão moderna" (Vaz, 2002, p. 11). No último capítulo, Vaz elabora um discurso no qual revela que, apesar de todos os desvãos da modernidade e de uma filosofia moderna pragmática e materialista, o Ser seja redescoberto e, com ele, a possibilidade de uma metafísica. É isso que o capítulo revela com o sugestivo título de "Esquecimento e memória do ser: sobre o futuro da metafísica". Tal obra, a última de Lima Vaz, reúne os textos escritos entre 1997 e 2001, e não faz referência direta ao conceito de "pósmodernidade", embora trate de uma nova visão de homem, ainda que de forma mais metafísica, que poderia fundamentá-la. Assim, permanece a pergunta do que então pode ser caracterizado como "pós-modernidade". Seria a alcunha mal formulada de uma nova modernidade que caracterize uma nova etapa daquele ciclo de sucessão, ou o anúncio de um "novo" sem precedentes que caracterize o fim do ciclo?

Como foi visto, a "modernidade moderna" tem um caráter paradigmático que a distingue das outras, tornando-se um marco que, de certa forma, rompe com o esquema de ciclo. Por ter sido, e continuar sendo, mais radical que as antecessoras, é ela também a que "patenteia seus limites e segrega [...] uma reação dialética e seus próprios princípios" (Sanchis, 1992, p. 46), ou seja, não é possível ser moderno do moderno. $\mathrm{O}$ advento de toda e qualquer "novidade" já pertence ao que se define por "modernidade moderna". Essa é a radicalização.

Nesse sentido, por Pós-modernidade devese compreender a ambigüidade que corresponde à própria Modernidade, isto é, ser "a continuação exacerbada e incandescente dos caracteres que acabamos de reconhecer, e sua contradição. Ao mesmo tempo em que ela confirma, ela questiona e problematiza" (Sanchis, 1992, p. 46). A Pós-modernidade pode ser considerada tanto a consagração das tendências "modernas" quanto seu contra-senso.

Para Sanchis, alguns traços dessa pósmodernidade podem ser percebidos, quando esta questiona e instaura uma nova relação com o tempo, quando estabelece uma relação poliva- 
lente entre indivíduos e os grupos, quando relativiza as noções do espaço e das identidades e, por fim, quando inaugura um novo olhar sobre a Verdade.

A relação unilinear da História com o tempo, orientado pelo vetor do progresso, passa a ser questionada e, ao "homem pós-moderno", já é possível prognosticar a abertura para um futuro indefinido, o que exige muitas vezes uma correção concreta de rumos. Além disso, o próprio projeto democrático é questionado, na medida em que a liberdade é tomada como princípio absoluto, implicando uma volutibilidade institucionalizada que impede a constituição de qualquer projeto de longo alcance, posto que não há garantias de estabilidade. Desse mesmo processo, surge o perigo dos fundamentalismos que, invertendo radicalmente a modernidade, buscam reencontrar uma eternidade.

Se, com a "modernidade moderna", o modelo que se firma ao nível das relações entre indivíduo e grupos são o da "Nação", com a "pós-modernidade" observa-se o "alargamento das relações de grandezas sociais em direção a totalidades cada vez mais amplas e abrangentes" (Sanchis, 1992, p. 47).

Ao mesmo tempo em que o modelo moderno continua sua trajetória de afirmação, ele manifesta, por um lado, o esgotamento de suas limitações e, por outro, começa a sofrer o embate das comunidades situadas em níveis inferiores que buscou sufocar. A revisão

pós-moderna das relações entre totalidades de níveis e naturezas diferentes, revisão que não deixa mais simplesmente face a face os dois adversários de ontem: o nacional e o internacional, nem dissolve o nacional específico na homogeneidade de um multinacional econômico ou cultural, mas que rearticula, de alto a baixo, níveis e instâncias do social como que numa operação de abertura. (Sanchis, 1992, p. 48)

A essa noção de "Nação" se articula, na "modernidade moderna", um sentido de delimitação espacial que conflita com a porosidade pela qual as fronteiras passaram a se apresentar na "pós-modernidade". O que leva Sanchis a se perguntar: "Será o nosso mundo capaz de estabelecer as condições, por fugazes e frágeis que sejam, para que se implante no espaço das trocas sociais o encontro plural e dialogal das culturas - não o seu confronto nem o simples rolo compressor da homogeneização - que nas suas vertentes mais positivas e ricas, a pósmodernidade aponta?". E responde: "perigoso desafio [...] mas se for vencido, [...] prodigiosa promessa" (Sanchis, 1992, p. 48).

Outra relativização empreendida no bojo da "pós-modernidade" seria a do conceito de identidade. Essa declinaria a noção de que, para reger a construção das identidades sociais, deveria ser observado o princípio estrito da lógica: não se pode ser isto e aquilo e, ainda, é impossível ao mesmo tempo ser e não ser. Ao contrário, o que parece se impor é uma construção compósita e sincrética. Isto se dá porque o nível definidor das visões de mundo não é mais o das instituições, mas o do indivíduo. Indivíduo que, diferente do homem moderno, "reencontra, em relação ao Todo com o qual ele se quer em comunhão, um laço participativo marcadamente emocional, que alguns julgam 'religioso"' (Sanchis, 1992, p. 49).

Por fim, o próprio regime da razão, fixado pela "modernidade moderna", é questionado. A imagem mais que o discurso, as narrativas parciais mais que as teorias recapitulativas, a emoção, a arte e o sexo para além do racional, é o que para o pós-moderno pode lhe permitir o encontro com a realidade, na qual é buscada, não uma "prova", mas um convencimento (Sanchis, 1992, p. 50).

\section{Uma sociedade "pos-tradicional"?}

Para Anthony Giddens (2001, p. 21), "vivemos em uma época de finalizações", de um século, de um milênio, ou mesmo, o "fim da modernidade". Não apenas o Ocidente, mas o mundo todo passa por um período de transição, que faz emergir o que ele caracteriza por uma "sociedade pós-tradicional". Com esse novo instrumento teórico, o sociólogo chama a atenção para o fato de que, apesar de a modernidade, por definição, colocar-se em oposição à tradição, na maior parte de sua história ela representou sua reconstrução, na medida que a dissolvia.

Com isso, à reflexão teórica duas esferas de transformação se apresentam. Por um lado, 
"há a difusão extensiva das instituições modernas, universalizadas por meio dos processos de globalização. Por outro, mas imediatamente relacionados com a primeira, estão os processos de mudança intencional, que podem ser conectados à radicalização da modernidade" (Giddens, 2001, p. 23). Esses são processos de abandono, desincorporação e problematização da tradição (Giddens, 2001). Esse movimento aponta para uma interdependência entre macro e microprocessos muito maior, isto é, as ordens globais têm cada vez mais influência no dia-adia dos indivíduos, e as decisões individuais geram cada vez mais resultados globais.

Impossível capturar toda a dimensão dessa nova realidade, por conta - e não apesar - do próprio conhecimento que se adquire sobre si mesmo e sobre o mundo, nesse período da "alta modernidade", como Giddens prefere denominar, o que outros pensadores, como Lyotard, denominam de "pós-modernidade". Certeza e perigo articulam-se, paradoxalmente, e apresentam-se de forma equilibrada, posto que, "quanto mais tentamos colonizar o futuro, maior a probabilidade de ele nos causar surpresas" (Giddens, 2001, p. 24). A modernidade passa a ser cada vez mais "experimental", mais desafiadora porque mais perigosa.

Essa aventura, querendo ou não, está articulada, efetivamente, à penetração das instituições modernas nos acontecimentos da vida cotidiana. Não apenas no que diz respeito ao eu e à identidade, mas, neste caso, refere-se também às mudanças ocorridas no dia-a-dia, no esforço de adaptação à tecnologia, por exemplo, e aos processos profundos de reforma da própria vida cotidiana. Aqui, Giddens anuncia um novo conceito, articulado ao de "alta modernidade", conceito de sociedade pós-tradicional. Ora, então por que chamar essa realidade de pós-tradicional, se a tradição parece não desempenhar mais nenhum papel? Para buscar-se a resposta, deve-se, entretanto, perguntar sobre o que é, efetivamente, tradição e o que caracterizaria uma sociedade tradicional. Por tradição, nomeiase o que mantém as ordens sociais em sociedades pré-modernas, mas, como não há uma conexão necessária entre repetição e coesão social, o seu caráter fixador e repetitivo suscita um maior esclarecimento. A noção de tempo volta a ser fundamental, uma vez que "a tradição é uma orientação para o passado, de tal forma que o passado tem uma pesada influência ou, mais precisamente, é constituído para ter uma pesada influência sobre o presente" (Giddens, 2001, p. 31).

O futuro também está incluso, posto que a repetição é a forma que a tradição encontra para organizá-lo sem o considerar como "um território separado". Há, então, inscrita à tradição uma noção de "persistência" e, ainda, de "memória", especificamente naquele sentido dado por Maurice Halbwachs (apud Giddens, 2001) de "memória coletiva", com uma força de agregação tanto moral quanto emocional. Com isso, o passado não pode ser considerado em sentido de preservação, mas em constante reconstrução, parcialmente individual, mas fundamentalmente social ou coletiva. "Por isso, podemos dizer que a tradição é um meio organizador da memória coletiva" (Giddens, 2001, p. 32).

Em sua definição, Giddens (1991) enfatiza na tradição seu caráter ritual que, ao ser interpretado, estabelece uma verdade formular, a que apenas alguns têm acesso, aqueles que passam a ser seus guardiões, conforme sua competência. Por fim, há ainda o conteúdo normativo ou moral da tradição, que indica o que se é e o que se deve ser, mas também oferece uma segurança ontológica aos que aderem a ela. Mas, como admite o próprio sociólogo, "a questão do que é uma 'sociedade tradicional' permanece sem solução" (Giddens, 2001, p. 35), apenas se pode dizer que é aquela em que a tradição exerce um papel dominante.

Daí, conclui-se que as sociedades modernas "se destradicionalizaram". Esse processo se compreende pelo fato de que a repetição, própria da tradição, pressupõe uma certa verdade que é a antítese da "indagação racional", opondo guardiões e especialistas, sabedoria e especialização.

Para Giddens, a modernidade destrói a tradição, mas há, num certo sentido, "uma colaboração entre modernidade e tradição [que] foi crucial às primeiras fases do desenvolvimento social moderno", o que permitiria falar de uma "tradição na modernidade" (Giddens, 2001, p. 73). 
As sociedades modernas, segundo o sociólogo, distinguem-se de todas as demais pelo desenvolvimento do capitalismo e do Estadonação, entretanto, as "primeiras instituições modernas tanto dependiam das tradições modernas, mas também criaram algumas novas", como chamou atenção Eric Hobsbawm (apud Giddens, 2001, p. 75).

As tradições, sejam elas antigas ou novas, permanecem fundamentais no desenvolvimento da modernidade. A ciência, em seu papel legitimador nas sociedades modernas, só fez perpetuar idéias de verdade que mantinham fortes laços com a verdade formular. Além disso, a tradição foi reivindicada particularmente com respeito à geração da identidade pessoal e coletiva (Giddens, 2001, p. 77-8).

Ao contrário, "a fase da "modernização reflexiva', marcada pelos processos concomitantes da globalização e da busca de contextos de ação mais tradicionais, altera o equilíbrio entre tradição e modernidade". A ordem "póstradicional" é marcada pela formação de um diálogo cosmopolita de toda a humanidade, em que as tradições não desaparecem totalmente, mas subsistem em duas estruturas como um discurso articulado e defendido como tendo um valor dentre tantos outros valores mais, ou como fundamentalismo.

A sociedade pós-tradicional é um ponto final, mas é, simultaneamente, um início, um universo de ação e de experiência verdadeiramente novo (Giddens, 2001). Trata-se de uma sociedade global, isto é, "de espaço infinito", na qual os elos sociais têm de ser criados e não mais herdados do passado, em um empreendimento cujas autoridades se encontram descentralizadas, mas as oportunidades e os dilemas estariam recentralizados. A condição de solidariedade social, no domínio do indivíduo, e, em uma escala mais ampla, uma ordem cosmopolita global estão eticamente implícitos nessa sociedade.

Há, portanto, uma pluralidade de estilos, de crença, de pertencimento e de caracterização cultural. O contexto dessa pluralidade efetivase em meio à crise, já mencionada, do projeto cultural/civilizatário da sociedade ocidental, crise que, segundo Agnes Heller, torna-se a própria essência da modernidade, seu modus operandi (Heller et al., 1999, p. 13).

A modernidade colocaria em permanente questionamento as forças da tradição, por isso a crise também é da tradição quando esta não comporta a opção individualizada em seu processo de institucionalização e da socialização como interiorização dos valores sociais a partir das grandes narrativas fundantes do convívio social. Esse modus operandi engendraria, na sua radicalização, a "pós-modernidade", ou o que chamam de modernidade tardia, alta modernidade, entre outras categorias (Giddens, 2002). Nessas situações, afirma Giddens (2002, p. 1011), a dúvida permeia a vida cotidiana, o "eu, como os contextos institucionais [...] em que existe, tem que ser construído reflexivamente. [...] essa tarefa deve ser realizada em meio a uma enigmática diversidade de opções [...]”. Em circunstâncias de incerteza e múltipla escolha, as noções de confiança e risco têm aplicação particular. Por outro lado, a noção de certeza, de verdade readquire nova relevância e visibilidade.

Entretanto, é preciso estar atento à singularidade do contexto ibero-americano, e particularmente brasileiro, ao refletir sobre essas mudanças, pois nele agem as complexas relações entre a dimensão do público e do privado, os dilemas e os impasses de um processo de modernização que não foi completado nem implementado da forma como idealizaram seus grandes reformadores, políticos estadistas.

Esse cenário levaria as religiões da tradição e instituições como a Igreja Católica a um processo de "dessubstancialização" da comunidade, uma crítica à "comunidade pensada como um grupo identitário fechado", expressa em fenômenos como a RCC e as aparições de Nossa Senhora (Steil, 1999). Nesse sentido, ao examinar a tipologia do pensador Ernest Troeltsch (mística, igreja e seita), Steil (1999) afirma que a ênfase do catolicismo tem recaído sobre o tipo místico e ao fazê-lo aproxima, em um mesmo nível analítico, o movimento carismático, as aparições de Nossa Senhora e as últimas elaborações de Boff. Isso também se deve, em parte, à perda de legitimidade dos "grandes relatos" totalizantes, ou seja, dos 
sistemas teóricos de caráter generalizante: partidos, família, escola e religiões institucionalizadas (Steil, 1999).

A religiosidade contemporânea teria assim seu vínculo com a herança (re)apropriado, entrando no âmbito da opção, da experimentação (Carvalho, 1994) e do consumo. Na dimensão religiosa, constata-se que existe uma "vontade de experimentação", singular em relação ao processo de adesão à religião que a regeu desde finais do século XIX até meados do século XX (Carvalho, 1994, p.23- 4). No entanto, a noção de experiência é algo estranho a muitas tradições religiosas (Carvalho, 1994, p. 26).

Paradoxalmente, há um processo de autonomização da experiência visível nos estratos urbanos de classe média, concomitantemente à profunda marca deixada pelo processo colonial de "sincretização" na religiosidade do Brasil. Populações européias, negras e indígenas, desenraizadas de suas culturas e topos originais, empreenderam suas práticas/crenças religiosas em um espaço "vazio", ou, no dizer de Sanchis, um espaço que provém (Sanchis, 1995, p. 124).

\section{A inter-relação entre cultura e religião}

Segundo Nestor Canclini (2000), antropólogo mexicano, a modernização da América Latina foi assimétrica, com diversas fases, que trouxeram diferentes demandas nas áreas em que, a partir do século XX, foi sendo implementada. A área econômica foi uma das principais portas da modernização, assim como a área cultural.

Contudo, o que os estudos clássicos (de sociologia, antropologia e outros) desprezaram foi a não-univocidade desse processo. Para Canclini (2000), esse processo foi e é um processo híbrido, particularmente quando se toma como foco de análise a estrutura urbana.

Em geral, as sociedades latinas vivenciaram intensos processos de migração e de mudanças nas formas de comunicação social, principalmente no século XX e, agora, no início do século XXI. Canclini (2000) afirma que, diante desses processos, é preciso repensar e desmontar os pares de oposição clássicos: subalterno/hegemônico, tradicional/moderno, comumente usados para falar do popular e, no caso, das religiões ditas populares. Há em curso nas sociedades latinas uma hibridação, ou seja, um processo que mescla estilos, influências, linguagens de comunicação, etnias, tradições de classes e mercado.

Canclini (2000) aponta três fatores desse processo: a intensa urbanização, o crescimento dos meios de comunicação convencionais (rádio, TV e jornais) e o desenvolvimento de novos meios de comunicação (internet). A pretensa homogeneidade de tribos e de vilas cede lugar a um espaço em que se intensifica uma "oferta simbólica heterogênea, renovada por uma constante interação do local com redes nacionais e transnacionais de comunicação" (Canclini, 2000, p. 285).

Nesse sentido, a cidade não pode ser encarada como uma enorme massa anônima, mas um emaranhado de grupos urbanos e sociais, vinculados pelos meios de comunicação. No palco dessas cidades, nos espaços públicos, há uma perda da visibilidade das estruturas macrossociais, onde emerge uma multiplicidade de movimentos urbanos, étnicos, juvenis, de consumidores que atravessam a cidade e a própria forma como as religiosidades se organizam nela. Assim, os processos atuais minam as totalizações clássicas: cultura urbana, cultura popular etc.

Há uma implosão dos cânones da modernidade que tentaram impor uma forma de organizar e classificar o tempo livre, as manifestações culturais, o consumo e o mercado, as relações de poder.

Canclini (2000) argumenta que existem dois processos em curso: o de desterritorialização (perda da relação "natural" da cultura com os territórios geográficos e sociais) e o de reterritorialização (relocalização territorial relativa, parcial, das velhas e novas produções simbólicas). Para comprovar isso, Canclini demonstra que tais processos de hibridação ligam-se à transnacionalização dos mercados simbólicos e aos intensos fluxos migratórios internos e externos na grande maioria das nações do planeta. Isso se relaciona com a indústria da cultura (filmes, novelas, livros etc.). Quanto às migrações, a multidirecionalidade é preponderante e não fica limitada apenas a políticos, a escritores e a artistas. 
Assim, Canclini (2000) vai percebendo que o modo de combinar modernização, ou semimodernização econômica, e a cultura nas sociedades latinas levam àquilo que tem sido chamado de pós-modernismo, remetendo à idéia de pósmodernidade, já discutida por Pierre Sanchis.

Mas como isso se manifesta nas religiosidades? Veja-se o avanço de religiosidades chamadas de neopentecostais ou pós-pentecostais, e isso em áreas não somente urbanas, mas em áreas fronteiriças e nas pequenas cidades do interior. No mapa religioso do Brasil, a região com o maior índice de diversidade religiosa é a do Acre, de Rondônia e proximidades.

A título de exemplificação da lógica da hibridação, coloque-se como exemplo a Igreja Universal do Reino de Deus. Sua lógica é mixar gêneros e estilos, referências e rituais. Uma hibridação que lança mão de mecanismos modernos de marketing. As correntes da prosperidade, correntes da libertação e do amor, divulgadas por essa igreja, contêm toda uma simbologia que remete a múltiplas influências, desde influências do catolicismo (água abençoada, cruzes e outros), até influências das religiões afro-brasileiras (sal grosso, arruda e o adorcismo/exorcismo das entidades da umbanda e candomblé). Isso para não mencionar a religiosidade absolutamente errante e nômade que é a new age ou, ainda, a expansão do culto do Santo Daime para o Sudeste brasileiro, até para a Europa, e dos cultos afro para os países do Mercosul (Argentina, Uruguai e Paraguai).

Enfim, mediante um cenário de interculturalidade, com o cruzamento de influências, de combinações, é preciso que sejam criados e repensados novos instrumentos conceituais de compreensão da realidade sociocultural-religiosa vislumbrada nas manchetes de jornal, nas TVs, no dia-a-dia das cidades e das vilas.

\section{O panorama do campo religioso brasileiro}

A partir dessa constatação de Canclini (2000), inicia-se uma breve apreciação do campo religioso no Brasil, finalizando-se com as pesquisas em andamento no Núcleo Regional do Cehila. Segundo Sanchis (2001), uma primeira constatação se impõe: a crescente diversidade religiosa e a progressiva perda da hegemonia do catolicismo no campo religioso, pelo menos em termos institucionais. Há uma pluralização das opções religiosas e dos estilos de crença e pertencimento, que é também interna nas grandes tradições religiosas, como o catolicismo (TFP, carismáticos, CEBs etc.) e o protestantismo (igrejas pentecostais, de cura divina e outras). Sanchis afirma que há um trânsito entre duas culturas presentes na sociogênese da nação brasileira, uma tradicional, católica-afrobrasileira, e uma moderna, da escolha individual e de identidades exclusivas.

Há uma lógica moderna na forma como o discurso dos católicos carismáticos, por exemplo, enfatiza a escolha individual e pessoal como um princípio fundamental na experiência religiosa. Por outro lado, há uma lógica pós-moderna, presente em correntes religiosas como a corrente new age, que propõe como dinâmica central a radicalização da escolha individual, aliada a um compósito de crenças, valores e ritos, desterritorializados de seus locais de origem e reterritorializados na trajetória individual da pessoa, que empreende uma busca espiritual pessoal e interior de seu "verdadeiro eu". Assim, parece existir uma intensificação do trânsito religioso, como modalidades pentecostais nas igrejas protestantes (correntes chamadas de "renovadas") e na Igreja Católica, com novas formas de expressão emocional e corporal (grupos de oração carismáticos e os padres cantores). Em um quadro sucinto (Quadro 1), Sanchis denomina as principais famílias ou filões no campo religioso brasileiro.

Há uma intensa circulação de significados entre esses filões, com afinidades e antipatias eletivas. Sanchis (2001, p. 31) argumenta que, de modo crescente e particularmente nos meios populares, "generaliza-se na sociedade brasileira um campo de comunicação marcado por intensos cruzamentos de fluxos de caráter religioso", ou, para usar os conceitos de Canclini (2000), intensos processos de desterritorialização e reterritorialização de ritos e de significados.

Para dar mais consistência empírica a sua argumentação, Sanchis (2001) cita uma pesquisa 
Quadro 1 - Filões do campo religioso brasileiro

\begin{tabular}{|c|c|c|}
\hline FILÃO RELIGIOSO & \multicolumn{2}{|c|}{ ESPECIFICAÇÕES } \\
\hline \multirow[t]{9}{*}{ Cristianismo } & \multirow[t]{4}{*}{ Catolicismo } & "Popular" \\
\hline & & Progressista (CEBs) \\
\hline & & Conservador (TFP) \\
\hline & & Carismático (RRC) \\
\hline & \multirow[t]{4}{*}{ Protestantismo } & Imigração (igreja luterana) \\
\hline & & Missão (metodista) \\
\hline & & Pentecostalismo (Assembléia de Deus) \\
\hline & & Neopentecostalismo (Igreja Universal) \\
\hline & Neocristãs & (testemunhas de Jeová, adventistas, LBV) \\
\hline \multirow[t]{2}{*}{ Afro-brasileiras } & \multicolumn{2}{|c|}{ Candomblé (jejê, nagô, jarê), tambor de mina, batuque } \\
\hline & \multicolumn{2}{|c|}{ Umbanda (esotérica, linha branca etc.) } \\
\hline Espírita & \multicolumn{2}{|l|}{ Kardecismo } \\
\hline Oriental & \multicolumn{2}{|c|}{ Seicho-no-iê, perfect liberty, meischu sama, budismo, hinduísmo } \\
\hline New age & \multicolumn{2}{|c|}{ Espectro cambiante de práticas/crenças/ritos } \\
\hline
\end{tabular}

Fonte: Sanchis (2001)

feita em Belo Horizonte sobre a audiência de programas religiosos dos meios de comunicação (rádio e programas de TV). Nessa pesquisa, Sanchis (2001) pinça alguns dados interessantes:

$\square$ os programas de rádio e TV do arcebispo Dom Serafim, em 1997, época da pesquisa, eram acompanhados por $49,1 \%$ dos espíritas kardecistas;

$\square 20,2 \%$ dos católicos olhavam ou acompanhavam diária ou semanalmente emissões evangélicas de rádio e TV;

$\square$ para os fiéis de outras religiões cristãs, na audiência a programas de rádio e TV evangélicos, esse índice subia para 50\%;

๘em relação aos pentecostais, $34 \%$ acompanhavam semanalmente o programa de Dom Serafim, e 33,4\% acompanhavam diariamente a programação da Rede Vida.

Contudo, o trânsito segue determinadas direções. Por exemplo, os espíritas não freqüentam programas pentecostais, e os fiéis do candomblé e da umbanda não assistem aos programas de rádio e TV de Dom Serafim. Isso sem falar nas questões semânticas, que mudam contextos e significados de textos sagrados, tradições e ritualidades. Basta lembrar a desterritorialização e a reterritorialização, nas acepções dadas por Canclini, que a Igreja Universal faz dos textos do Antigo Testamento, associandoos à teologia da prosperidade, em uma interpretação oposta àquela dada pelo catolicismo progressista da Teologia da Libertação. A religiosidade new age, por exemplo, tem como condição estruturante justamente essa lógica sincrética ou de hibridação que a impede de ser localizada em uma instituição, um dogma ou um território específico. Entretanto, esses territórios não têm fronteiras fixas, mas fronteiras borradas e móveis. Assim, mesmo em religiosidades de cunho moderno, como a dos carismáticos, podem ser identificadas aproximações com o universo da pós-modernidade, quando os carismáticos enfatizam a experiência emotiva como critério da veracidade, a crença em um mundo encantado (onde se vislumbram batalhas entre anjos e demônios e onde a alma recebe os eflúvios do Espírito Santo). Os exemplos poderiam ser multiplicados.

No entanto, para finalizar as breves considerações que este artigo pretendeu emprestar ao debate sobre a modernidade e a religião, é 
necessário traçarem-se, ainda que em linhas largas e grossas, algumas conclusões. ${ }^{1}$

Primeiro, tradição, modernidade e pósmodernidade não podem ser vistas como etapas temporais que se sucedem ao longo do tempo, uma se extinguindo com o advento da próxima, mas como sensibilidades, mentalidades, estilos, que moldaram civilizações e que continuam convivendo, negociando, antagonizando-se e compondo-se tanto na contemporaneidade quanto em outras épocas.

Como modalidades sociais e culturais, essas dimensões influem e recebem influência da religião que, nesse processo, também assume características tradicionais, modernas ou pós, ou, como frisado, compõe ou guarda tensões entre tradição e modernidade dentro dela.

Segundo, as continuidades e descontinuidades da modernidade e da religião abarcam, entre outros fenômenos, as devoções populares, como a pouco pesquisada devoção a São Longuinho em Freguesia (Guararema, cidade do interior paulista), baseadas em uma poderosa tradição oral, e por isso mesmo, sujeitas a reinvenções na modernidade.

Isso abarca também o culto aos santos em geral. ${ }^{2}$ Com o advento do culto aos santos, os cemitérios - por excelência as cidades dos mortos - não só passaram a integrar as cidades dos vivos, bem como, no lugar de antigos cemitérios, surgiram santuários que, paulatinamente, deram origem a novas cidades, redesenhando o mapa do mundo conhecido.

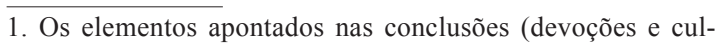
tos aos santos, vida religiosa alternativa etc) trata-se na verdade de estudos e pesquisas em andamento no Núcleo do Cehila regional de Minas Gerais, com sede em Juiz de Fora. Essas pesquisas têm sido desenvolvidas por parte de historiadores, sociólogos e antropólogos, em uma equipe multidisciplinar que trabalha há quatro anos neste e em outros projetos. Citam-se aqui os nomes dos pesquisadores: Elam Pimentel, Simone Santos, Mabel S. Pereira, Joelma Duarte, Ana Lúcia Meyer, Marcelo Camurça, Eduardo Crochet, Simone de Oliveira, Valéria Ferenzini e Emerson Sena da Silveira.

2. O surgimento e o progresso do culto aos santos, a partir do século III d.C., provocaram grande impacto sobre a organização social, espacial e mesmo política da sociedade. A primeira grande novidade foi o rompimento da fronteira entre a 'cidade dos vivos' - onde a vida social, econômica e política se realizava - e a 'cidade dos mortos' - precisamente representada pelos cemitérios, o lugar dos excluídos, daqueles que não atuavam mais neste mundo, precisamente os mortos.
Quanto ao plano político, os bispos cristãos fortaleceram seu poder assumindo o controle desses 'santuários' e das devoções e santificações. Assim, túmulo e altar foram reunidos, o que resultou no reforço da autoridade religiosa sobre o mundo dos vivos.

No Brasil, a devoção aos santos chegou com os colonizadores e se enraizou dando margem à existência de santos para tudo, para problemas de procriação até questões financeiras. Nesse aspecto, devem-se ressaltar as tentativas de controle por parte da hierarquia eclesiástica a partir do século XVIII, com atenção para "as Constituições Primeiras do Arcebispo da Bahia de 1707". A partir do século XIX, o processo de romanização e reforma católica ultramontana e suas diretrizes no tocante ao culto dos santos imprimem novas mudanças, que têm continuidade no Concílio Vaticano II e seus documentos.

$\mathrm{Na}$ prática, em virtude da organização inicial da Igreja Católica, os católicos orientaram a sua devoção pelo ritmo do calendário litúrgico. A "proteção" dada pelos santos diante das incertezas da vida tornou-se núcleo estruturante das crenças e das práticas mais difundidas. $\mathrm{O}$ culto e os rituais em torno dos santos realizamse sob a égide de performances cada vez mais diferenciadas e inovadoras. Os santos estão em adereços da moda, altares virtuais, tornam-se figuras pop, fashion. "Velhas devoções" são revitalizadas e outras "novas devoções" ganham prestígio entre os devotos, sendo essas reconhecidas ou não pelas autoridades eclesiásticas. Aqui, são interessantes as "santidades" populares; citam-se como exemplo figuras femininas do estado de Minas Gerais: Palmira (Juiz de Fora), Lola (Rio Poma) e Nhá Xica (Baependy).

Talvez seja possível dizer que a tradição devocional aos santos no Brasil permaneceu ao longo de todos esses séculos, apesar das diversas tentativas de controlá-la. Há, em andamento, novas combinações que tal sistema devocional desenvolveu, em especial com as novas tecnologias de comunicação; por exemplo, os altares virtuais dos santos católicos na internet.

Outras áreas de entroncamento entre modernidade e religião podem ser vistas na vida religiosa alternativa feminina no Brasil ao longo do século XIX: as beatas, que eram mulheres 
freqüentemente motivadoras de controvérsias em função de uma religiosidade repleta de manifestações de êxtases, práticas de jejuns e mortificações. O que se percebe é que a Igreja buscou constantemente se apoiar sobre os relatos médicos (a medicina alopática é um dos aspectos mais fundamentais da modernidade) que descreviam os fenômenos extáticos na categoria de "anormalidade" das funções biológicas. O discurso das autoridades religiosas aproxima-se dos discursos da medicina científica, sugerindo uma interação entre saberes médicos científicos e religião.

Ainda dentro do catolicismo, pode-se citar o arco que se estende entre as práticas de caridade e o terceiro setor (ONGs), ou seja, as práticas de um catolicismo social. Os mandamentos instituídos na mensagem de Jesus se traduziram desde os primeiros séculos em uma prática de partilha entre os membros das comunidades cristãs e de caridade para com os mais desfavorecidos. Com a oficialização da religião católica, tais práticas receberam também um caráter oficial, vindo a se conformar em doutrina da Igreja. A evolução dessa doutrina está no centro de diversas transformações por que passou o cristianismo, quando do surgimento das ordens mendicantes ou por ocasião da grande cisão, representada pela Reforma Protestante, para citar apenas dois grandes marcos. Transformações não apenas oficiais, mas, sobretudo, nas práticas cotidianas da vivência religiosa. $\mathrm{O}$ século XX representa um marco nas transformações da face social do cristianismo, uma vez que a preocupação com o retorno da mensagem cristã mais autêntica encontra-se com uma necessidade de abertura para os desafios do mundo contemporâneo.

Saindo do catolicismo, podem-se mencionar as religiosidades contemporâneas em que a religião se "subordina" ao indivíduo, e é ele próprio quem elabora seu universo simbólico, tendo a sua disposição uma gama de bens culturais que são (re) elaborados de forma livre e subjetiva, envolvendo uma magnífica diversidade de símbolos. Esse seria o universo denominado de new age.

Uma quinta área de confrontação entre modernidade e religião poderia ser encontrada entre os projetos educacionais de caráter confes- sional (os mais importantes nesse sentido são a saber: o metodista e o católico, cujo ápice do confronto é o período da Primeira República) que, não obstante estivessem baseados em diferentes modelos de educação, tinham por objetivo comum modernizar o Brasil através da formação das elites. Isso se relaciona, com efeito, à percepção, por parte das elites republicanas, do ensino metodista, baseado no modelo norte-americano, considerado "moderno" em relação ao tradicional ensino católico, cujo modelo era o europeu.

Embora esses dois modelos de educação fossem diferentes, até certo ponto, contraditórios $\mathrm{e}$, justamente por isso, tenham entrado em choque, ambos pretendiam servir como referência para a construção de uma nação moderna e civilizada. Assim sendo, as tensões entre metodistas e católicos no campo educacional da Primeira República revelam uma contenda mais ampla: o embate entre projetos de modernidade.

Por fim, uma sexta área de confrontação entre modernidade e religião, que seria o consumo de itens como livros, vestuários e artesanato associados às religiosidades. Podese analisar, como exemplo, livros e publicações e as estratégias que os diferentes leitores desenvolvem diante da intrincada teia de associação entre símbolos religiosos, que emergem desses itens de consumo, no caso, os livros.

Nesse sentido, as imagens e os símbolos associados à religião passaram a irromper de dentro da própria modernidade, ou seja, a religião assumiria modos de ser tidos como modernos, particularmente a partir de dois elementos: a decisão e a escolha pessoal e o marketing aplicado ao conteúdo religioso de igrejas e de credos. Enfim, pode-se dizer que entre a modernidade e a religião não há um caminho único (ruptura, combinação ou permanência), mas múltiplos caminhos, que se intercruzam constantemente na história das práticas religiosas e no seu efetivo exercício (com o imaginário e outras questões aí implicadas) em interface com a indústria cultural da sociedade contemporânea.

\footnotetext{
Abstract: To reflect about the modemity and its relation to religion is thinking about the role of tradition, the changing's in course in the cultural sphere and its
} 
consequences for the manifestation of the religiosity diversities. From the point of view, it's necessary to disnaturalise concepts as the modemity one, showing the existence of multiple meanings in the concepts and the reality unfold. Therefore, it points out to new possibilities as the hybridity between creeds and oultural and religious practices.

Key-words : modemity; religion; social theories, brazilian religiaus field.

\section{Referências}

CANCLINI, Néstor García. Culturas híbridas: estratégias para entrar e sair da modernidade. São Paulo: Edusp, 2000.

CARVALHO, José Jorge. O encontro de velhas e novas religiões: esboço de uma teoria dos estilos de espiritualidade. In: MOREIRA, Alberto \& ZICMAN, Reneé (Org.). Misticismo e novas religiões. Petrópolis (RJ): Vozes, 1994.

GIDDENS, Anthony. Em defesa da sociologia. São Paulo: Editora Unesp, 2001.

. Modernidade e identidade. Rio de Janeiro:

Jorge Zahar, 2002
HELLER, Agnes et al. A crise dos paradigmas em ciências sociais e os desafios para o século XXI. Rio de Janeiro: Contraponto, 1999.

PLACE, Robert. Tarô dos santos. São Paulo: Ediouro, 2001.

SANCHIS, Pierre. O campo religioso será ainda o campo das religiões? In: HOORNAERT, E. (Org.) História da Igreja na América Latina e no Caribe. Petrópolis (RJ): Vozes, 1995.

. Modernidade e pós-modernidade. Análise \& Conjuntura. Belo Horizonte, v. 7, n. 2 e 3, maio/ dez. 1992.

Religiões, religião... alguns problemas do sincretismo no campo religioso brasileiro. In:

(Org). Fiéis e cidadãos: percursos de sincretismo no Brasil. Rio de Janeiro: EdUerj, 2001. p. 9-58..

STEIL, Carlos. A igreja dos pobres: da secularização à mística. Religião e Sociedade, vol. 19, n. 2, Rio de Janeiro: CER/Iser, 1999.

VAZ, Pe. Henrique C. de Lima. Escritos de filosofia VII: Raízes da modernidade. São Paulo: Edições Loyola, 2002. 